\title{
How Could the Gold King Mine Water be Passively Treated?
}

\author{
Jim Gusek, P.E. \\ Sovereign Consulting Inc. \\ Lakewood, Colorado
}

GEOLOGICAL SOCIETY OF AMERICA

ANNUAL MEETING - DENVER, COLORADO

GOLD KING MINE SPECIAL SESSION 


\section{Outline}

- Gold King Mine Thumbnail Sketch

- Passive Treatment Biogeochemistry

- Two Gold King Passive Treatment Design Concepts 


\section{The Gold King Site}

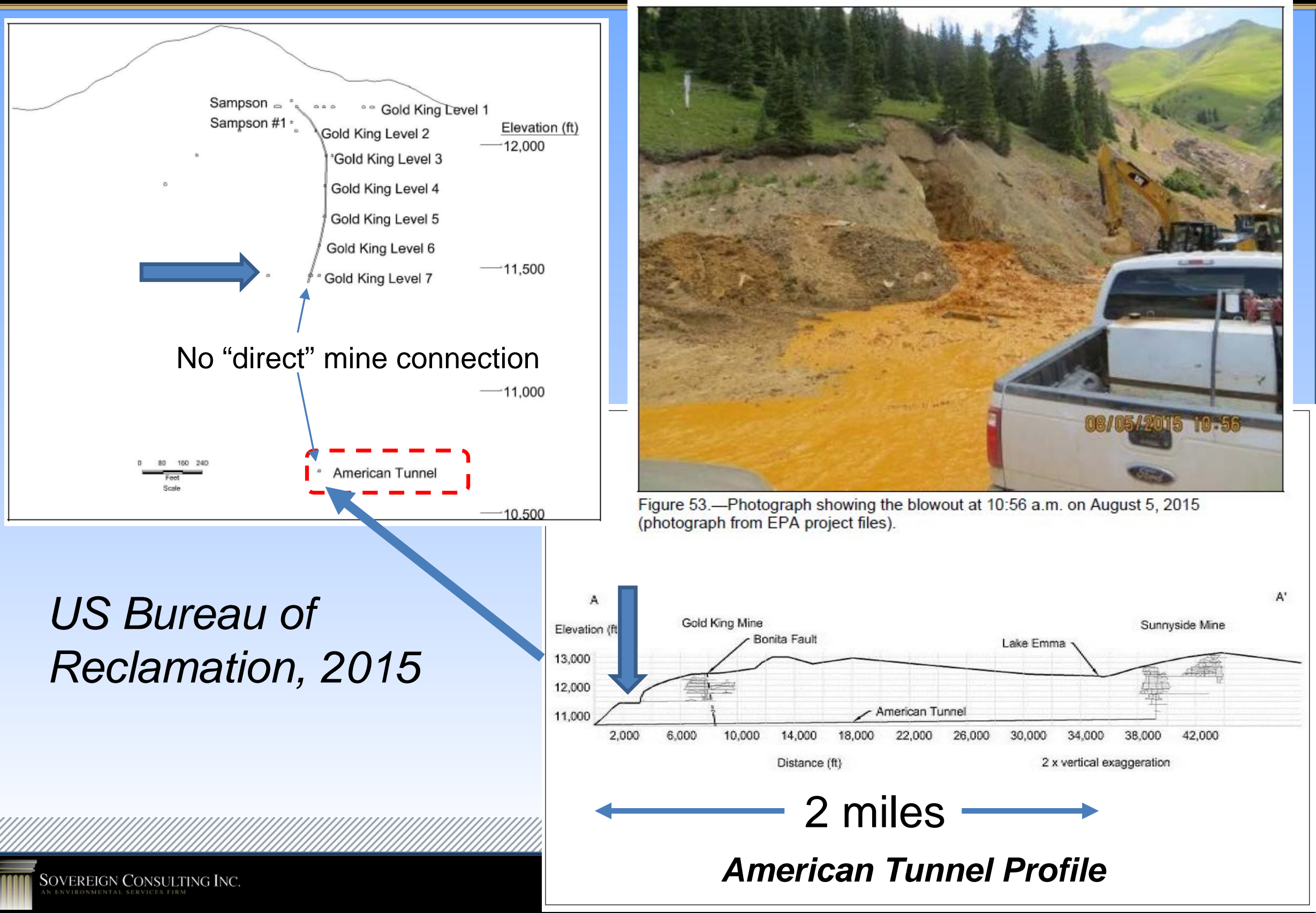




\section{"Natural" Attenuation}

Mother Nature is pretty talented; to remediate heavy metals situations, She uses:

Sequential

Ecological

extraction

processes that have evolved over

millennia (Thanks, C. Darwin) 


\section{What Is the Passive Treatment Process?}

Passive Treatment of MIW involves the:

\section{Sequential Ecological extraction}

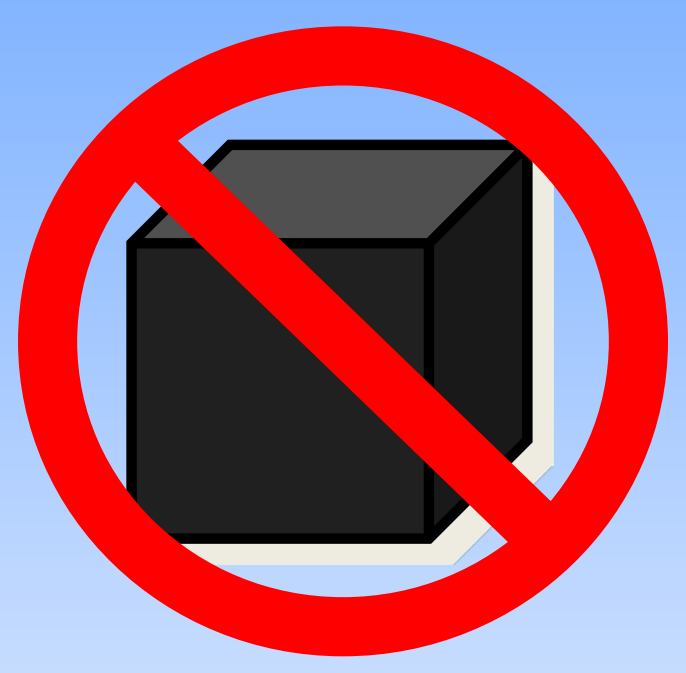

Of metals in a man-made but naturalistic bio-system 


\section{Iron Stromatolites \& Fe/Mn Nodules}

\section{Shark Bay, Australia}
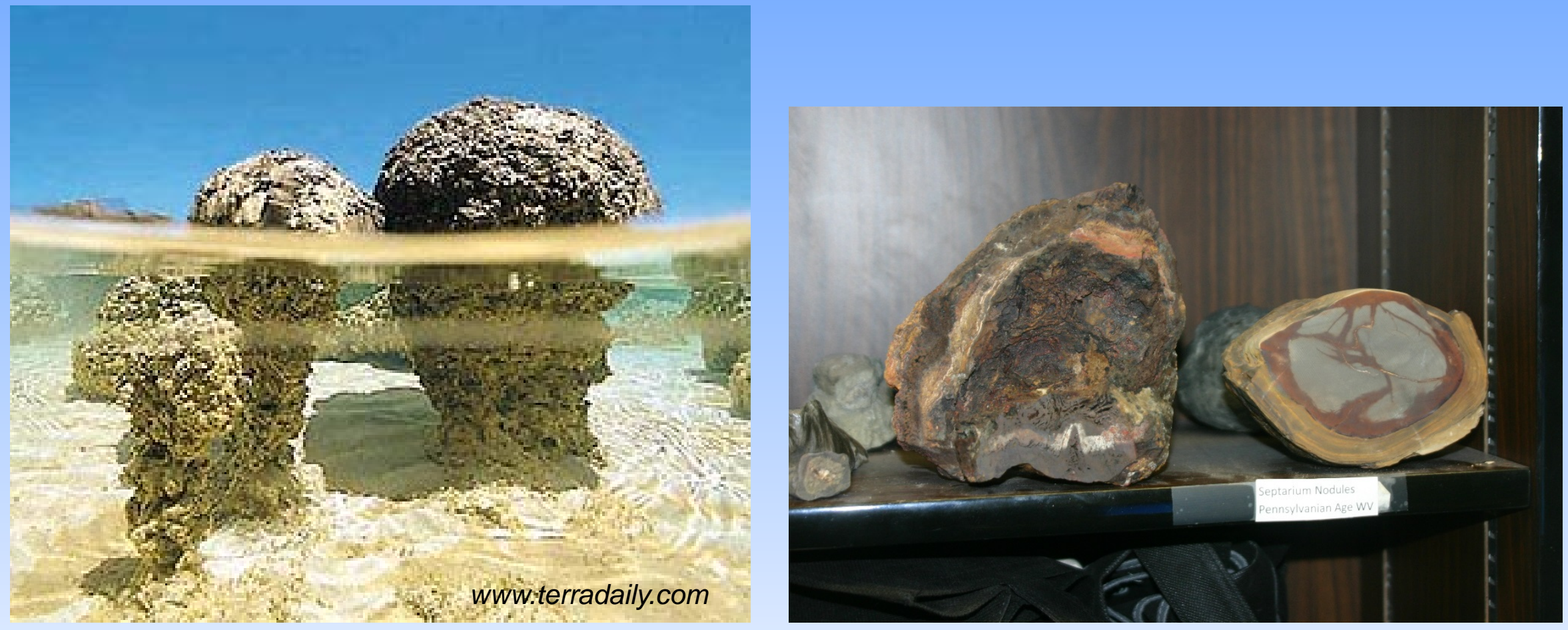

Stromatolites built by cyanobacteria/algae, a Fe/Mn Fossil Nodules Courtesy of Nick Shearer, WV DEP process over 1 billion yrs old 


\section{Ferricrete Deposits}

\section{Animas Basin, Colo.}

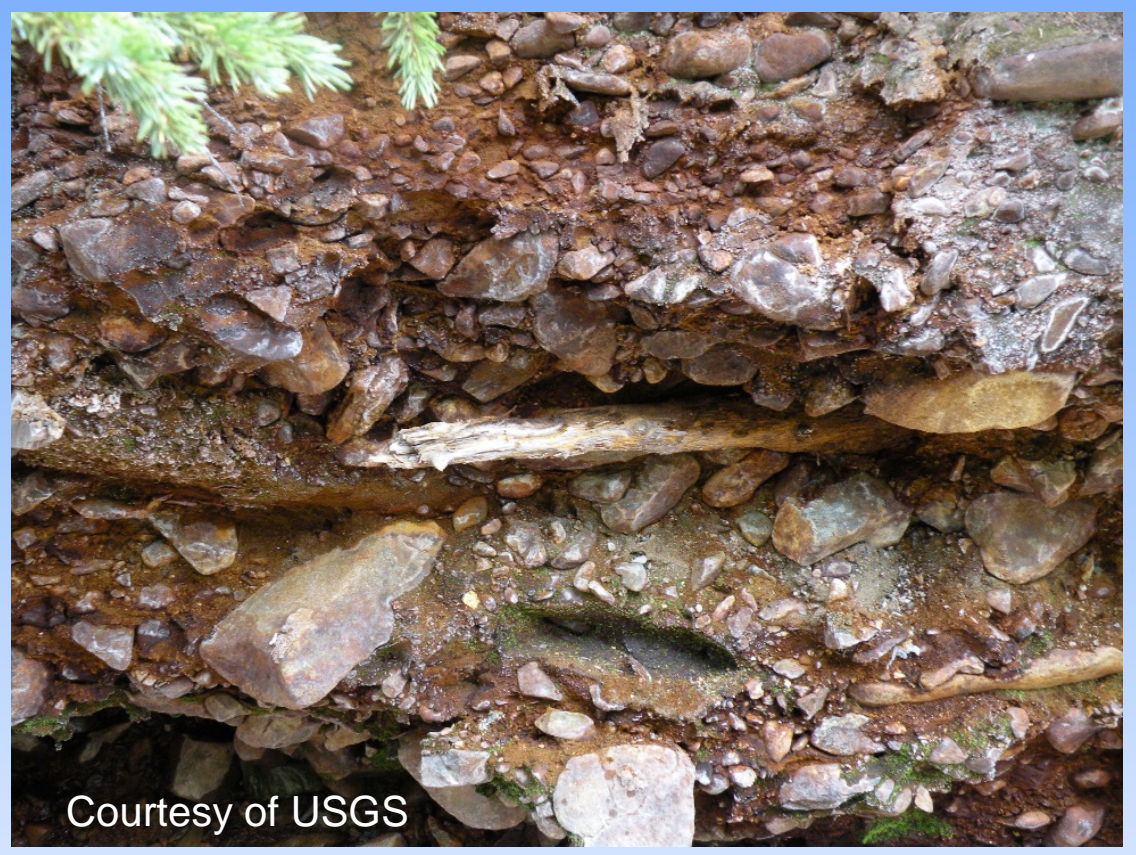

Deposit of iron-cemented stream gravel (ferricrete) with embedded wood fragments

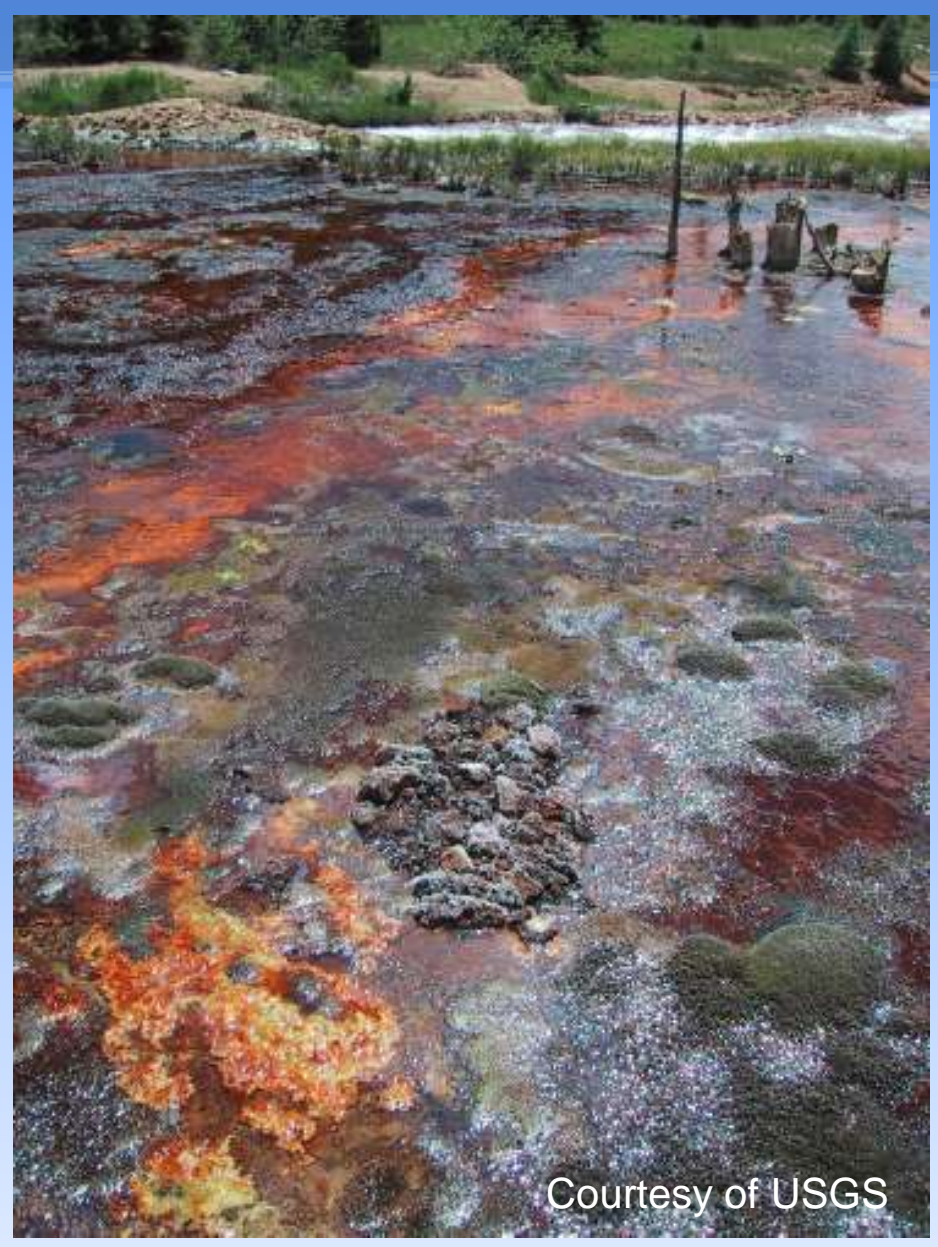

Natural Iron-rich Acidic Spring Flowing into Cement Creek. 


\section{Manganocrete Deposits}

\section{Animas Basin, CO \& Patagonia, AZ}

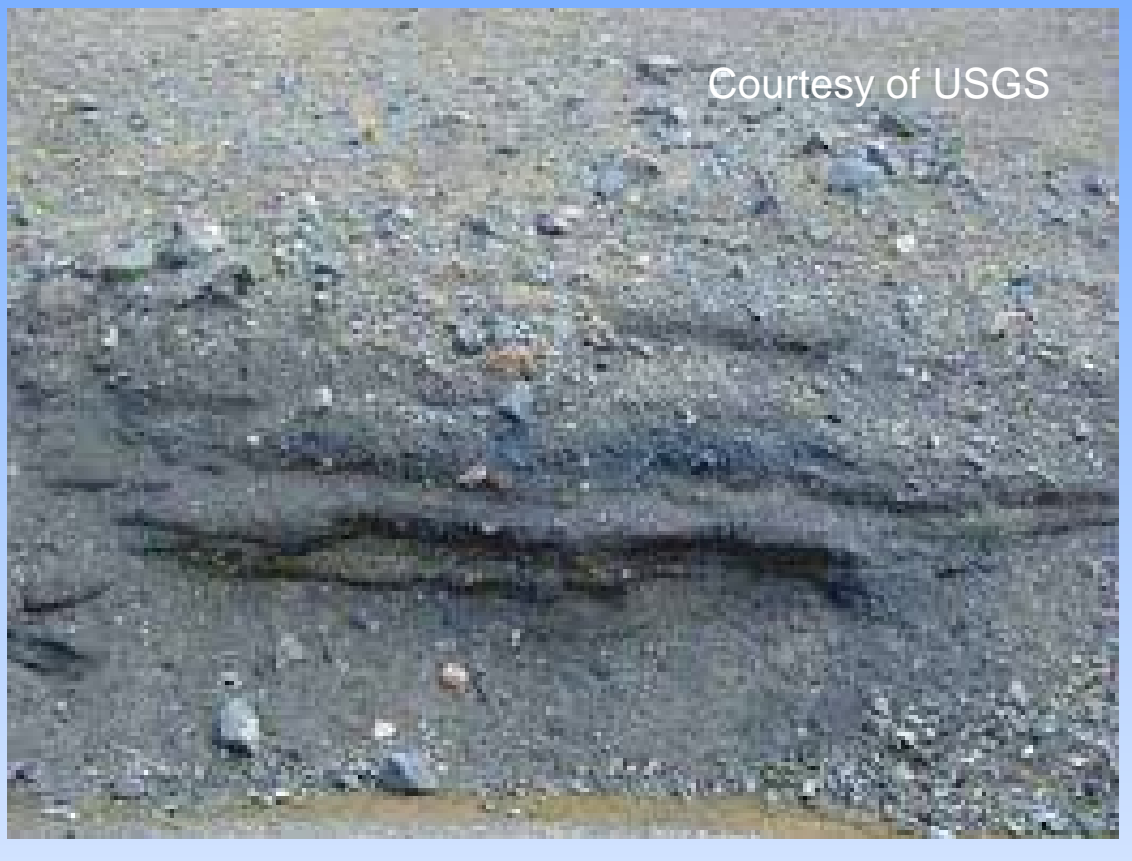

Alluvial manganocrete near the former Lake

Emma in Eureka Gulch

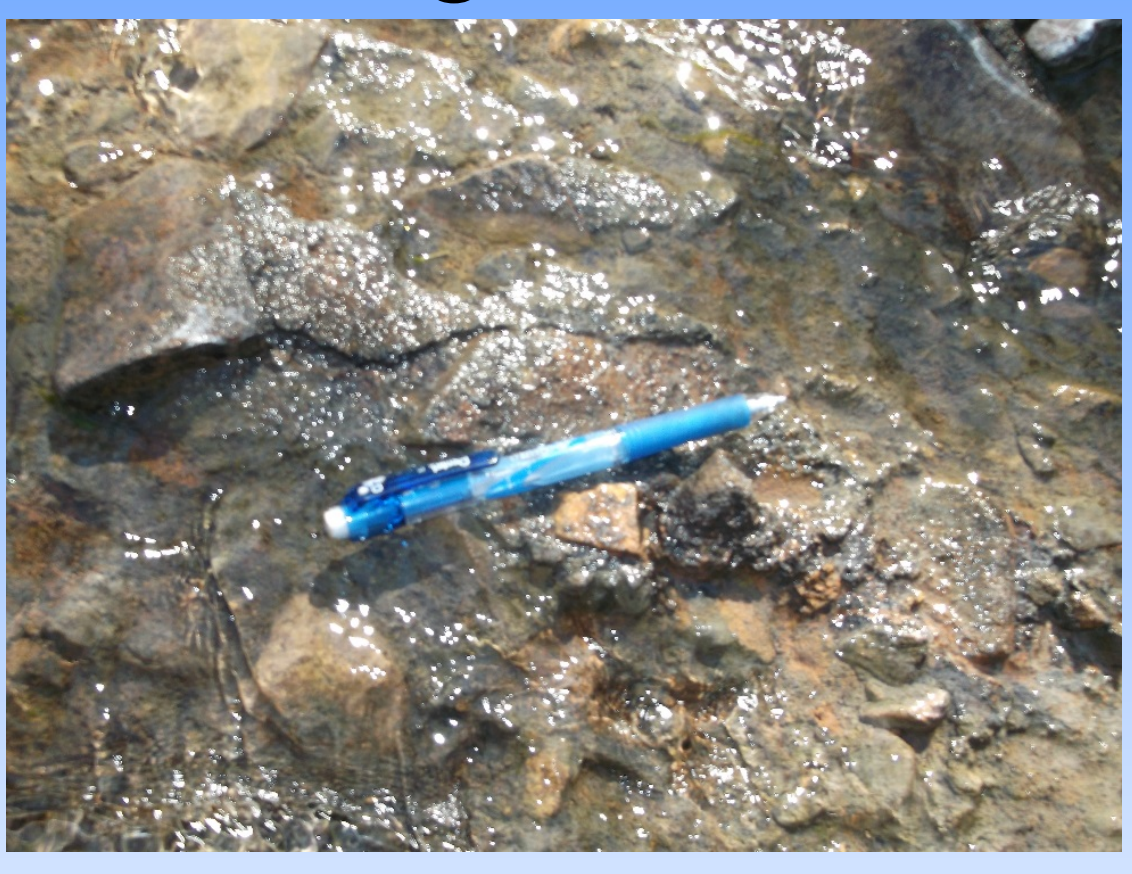

$\mathrm{MnO}_{2}$-cemented alluvium in Alum Creek 


\section{Natural Metal Removal Mechanisms}

- Sulfide and carbonate precipitation via sulfate reducing bacteria, et al.

- Hydroxide and oxide precipitation by acidithiobacillus ferro-oxidans bacteria, et al.

- Filtering of suspended materials and precips

- Carbonate dissolution/replacement

- Metal uptake into live roots, stems and leaves

- Adsorption and exchange with plant, soil and other biological materials 


\section{Periodic Table of Passive Treatment}

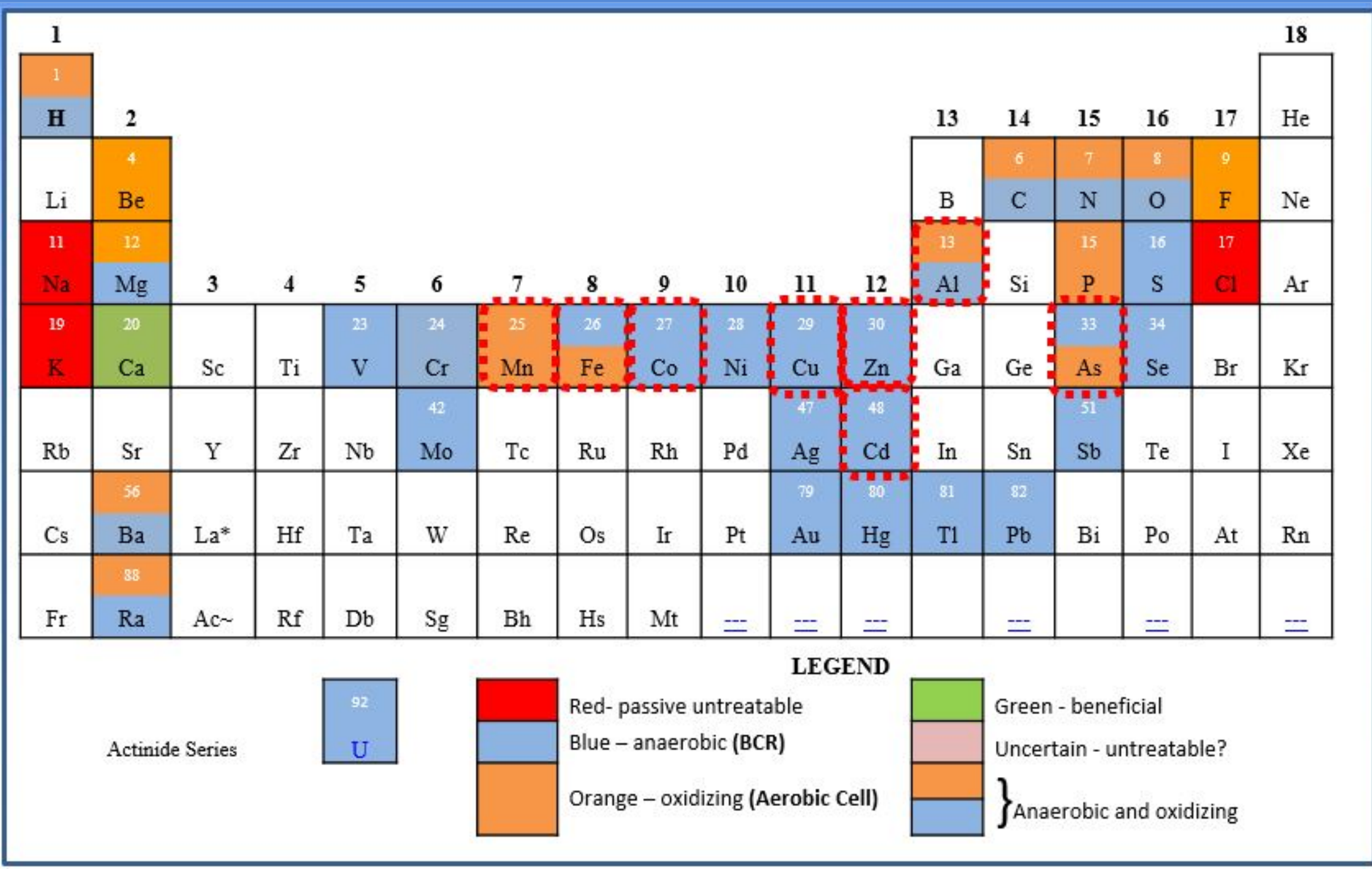




\section{Periodic Table of Passive Treatment Re-Visited}

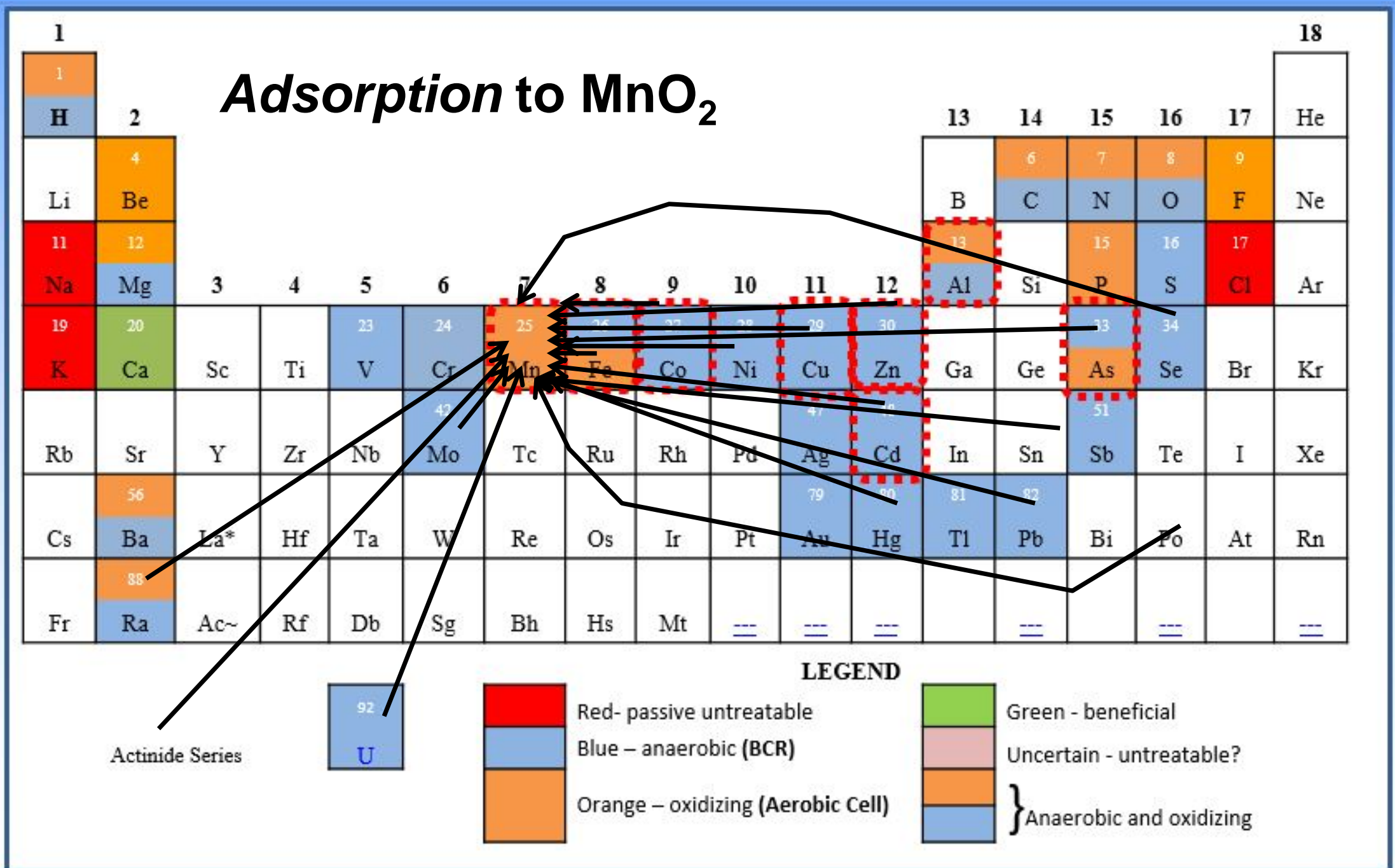




\section{Anaerobic Biochemical Reactors (BCRs)}

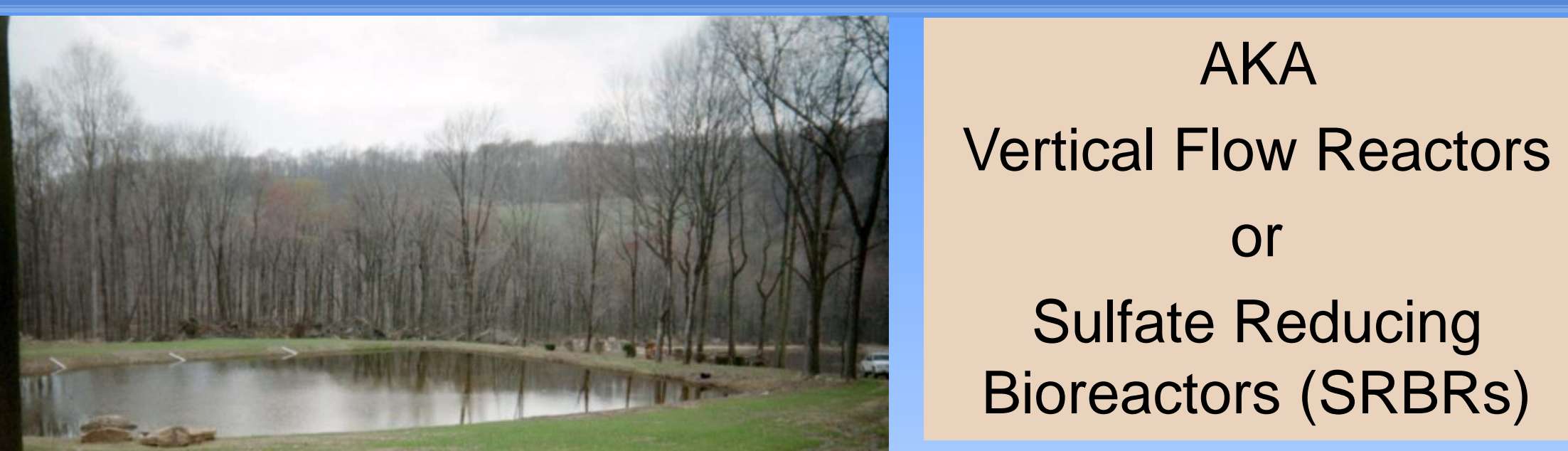

Aluminum and heavy metal removal, selenium removal, de-nitrification, $\mathrm{pH}$ adjustment, alkalinity $\&$ hardness addition

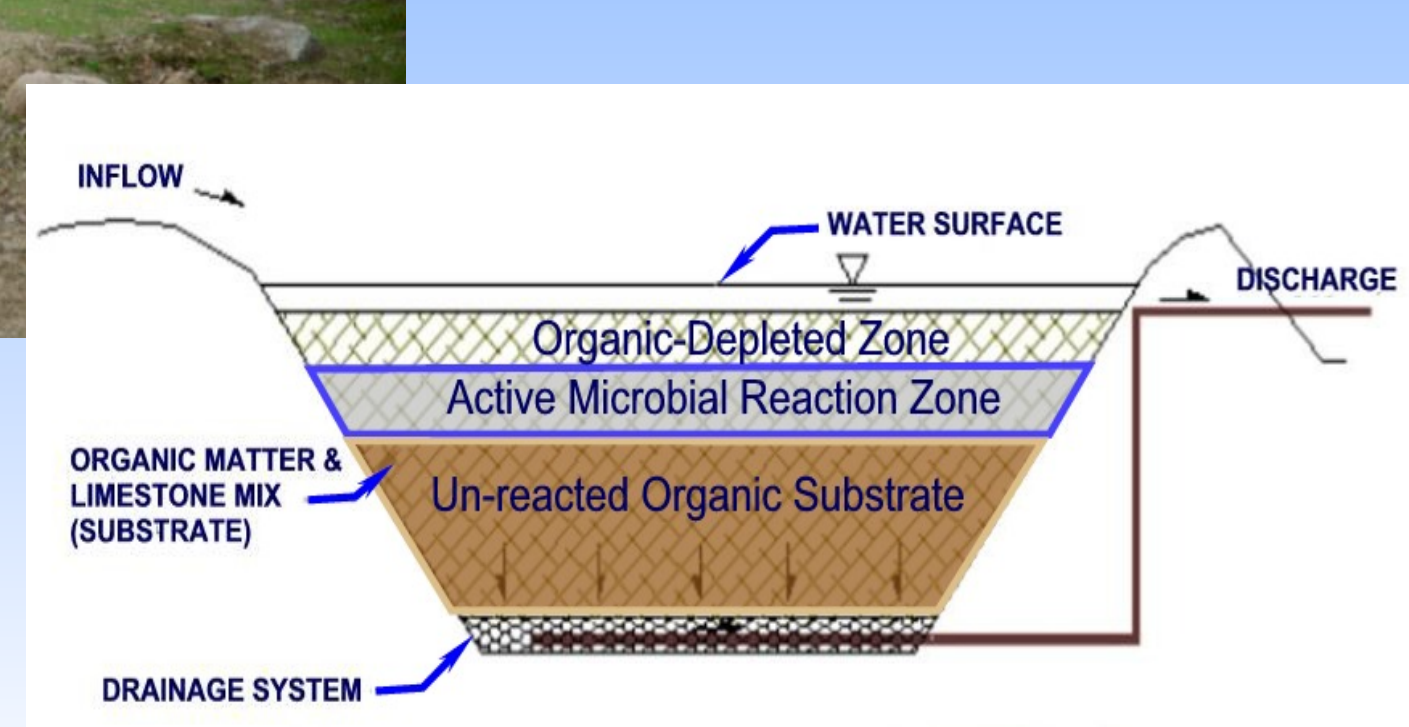




\section{Aerobic Cells}
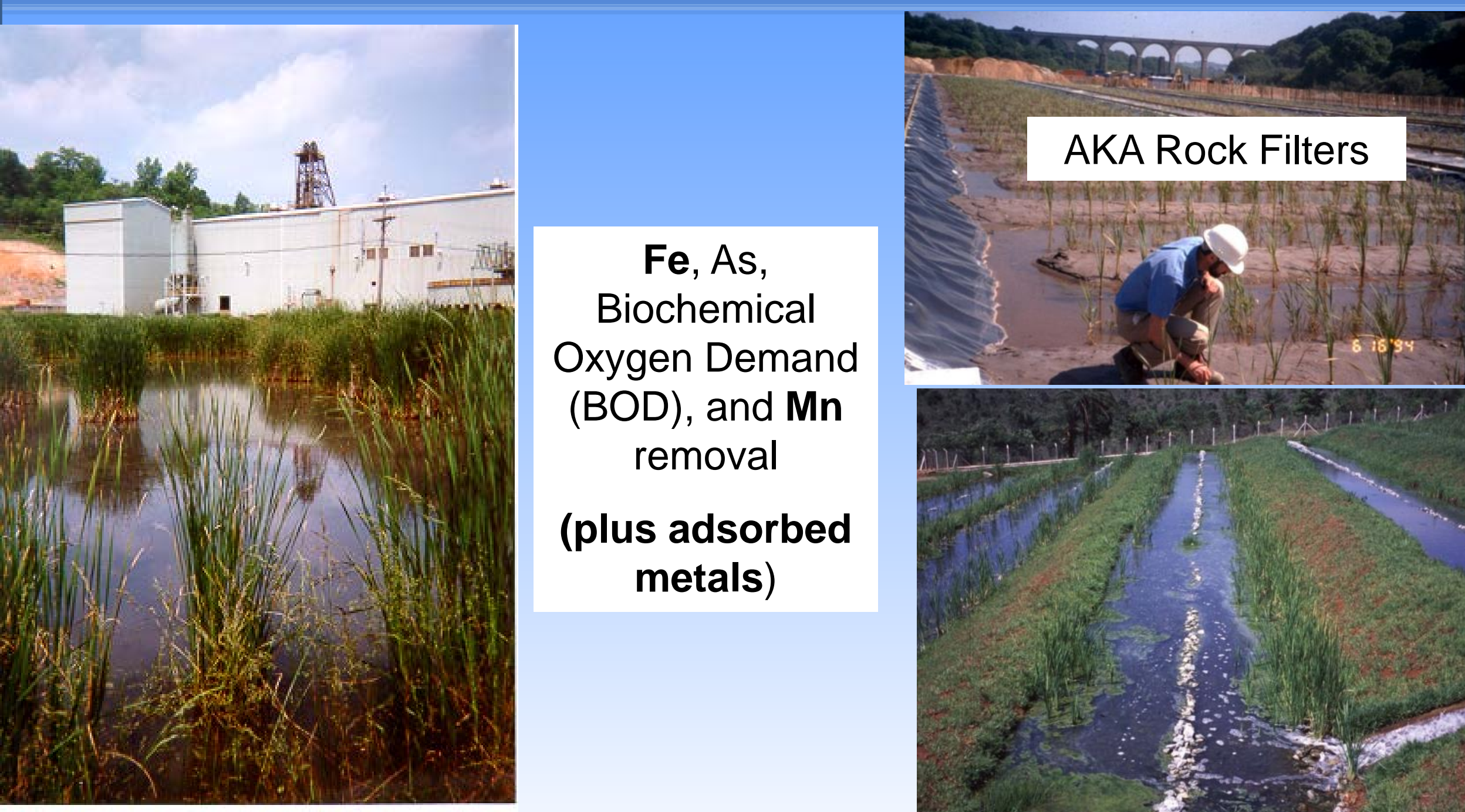

removal

(plus adsorbed metals)

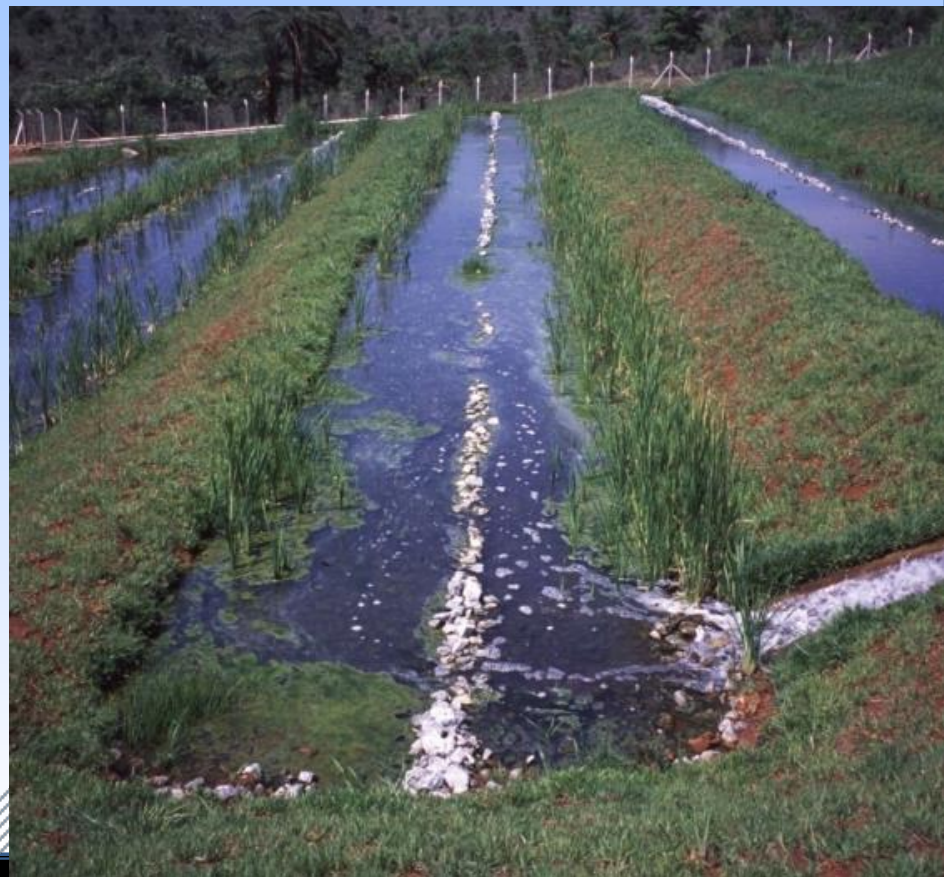




\section{Iron Terraces - Aerobic Special Case}

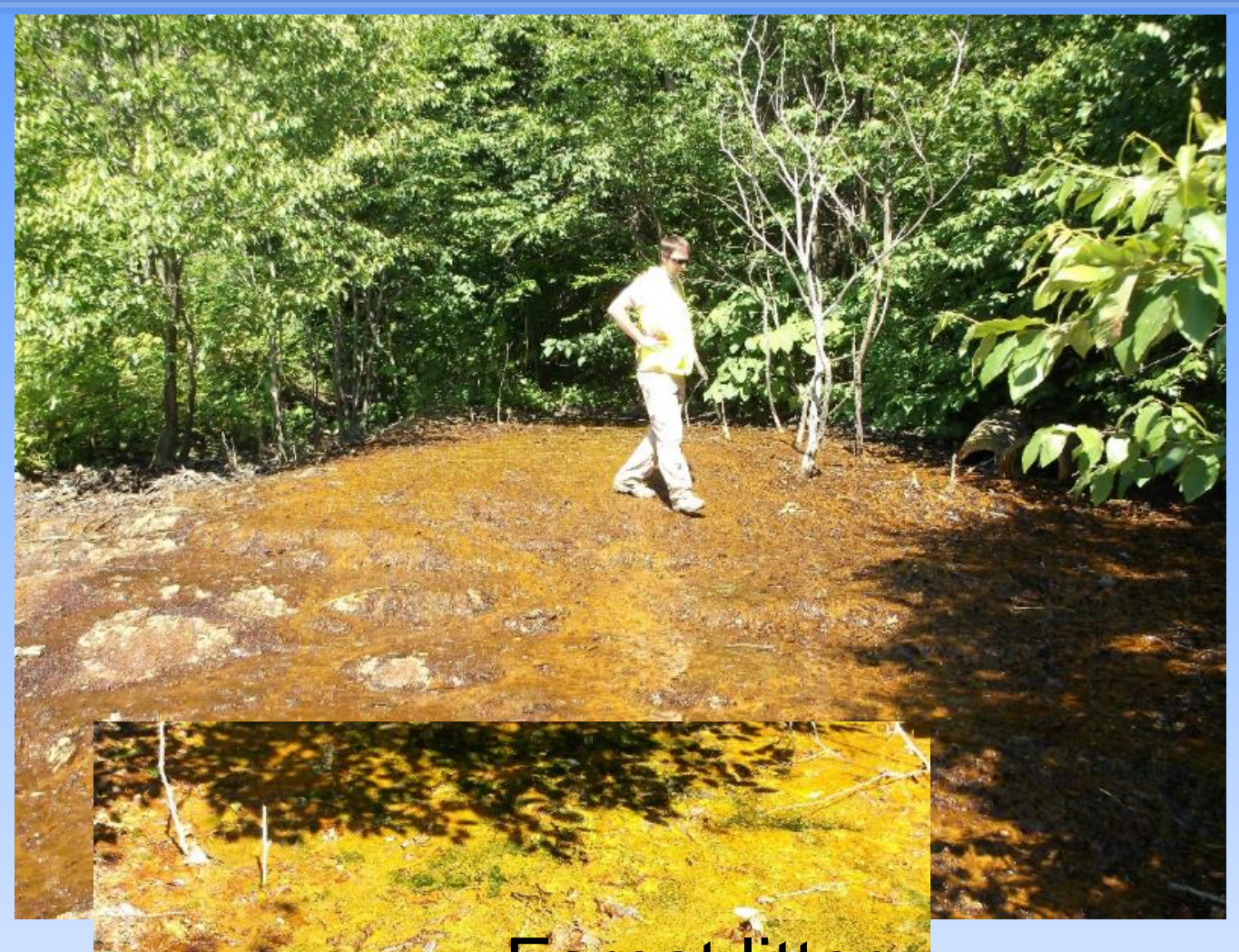

Modern Aerobic Wetlands \& Ferricrete/Iron Terraces

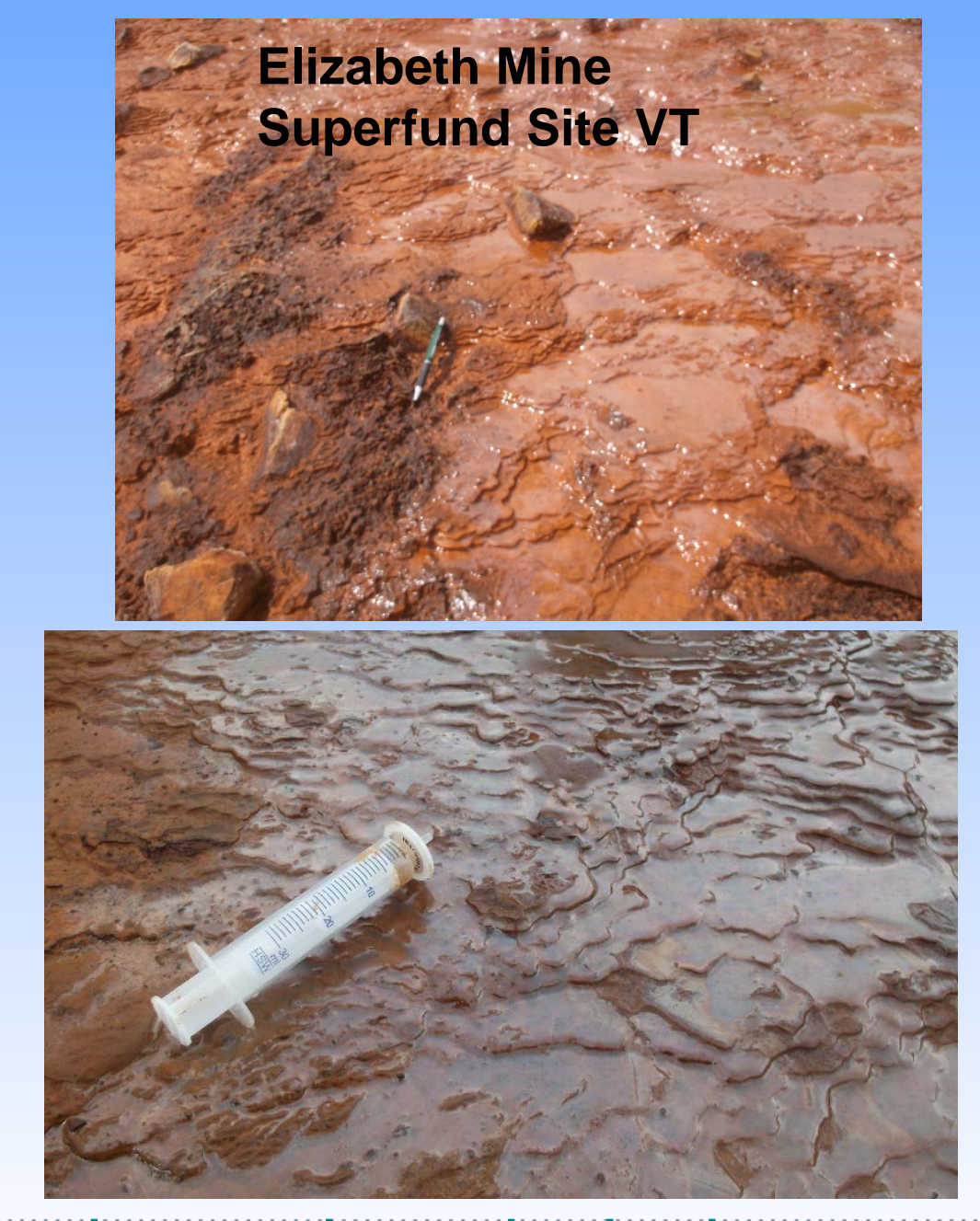

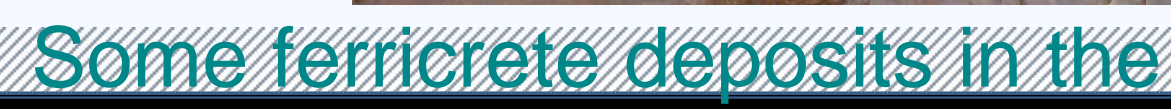




\section{Natural Treatment Chemistry 102}

\section{IRON TERRACE REACTIONS}

$6 \mathrm{H}^{+}+\left(\mathrm{C}_{6} \mathrm{H}_{10} \mathrm{O}_{5}\right) \mathrm{n}+3 / 2 \mathrm{O}_{2} \square 6 \mathrm{C}+16 \mathrm{H}_{2} \mathrm{O}+$ heat (Cellulose Dehydration by Acidity)

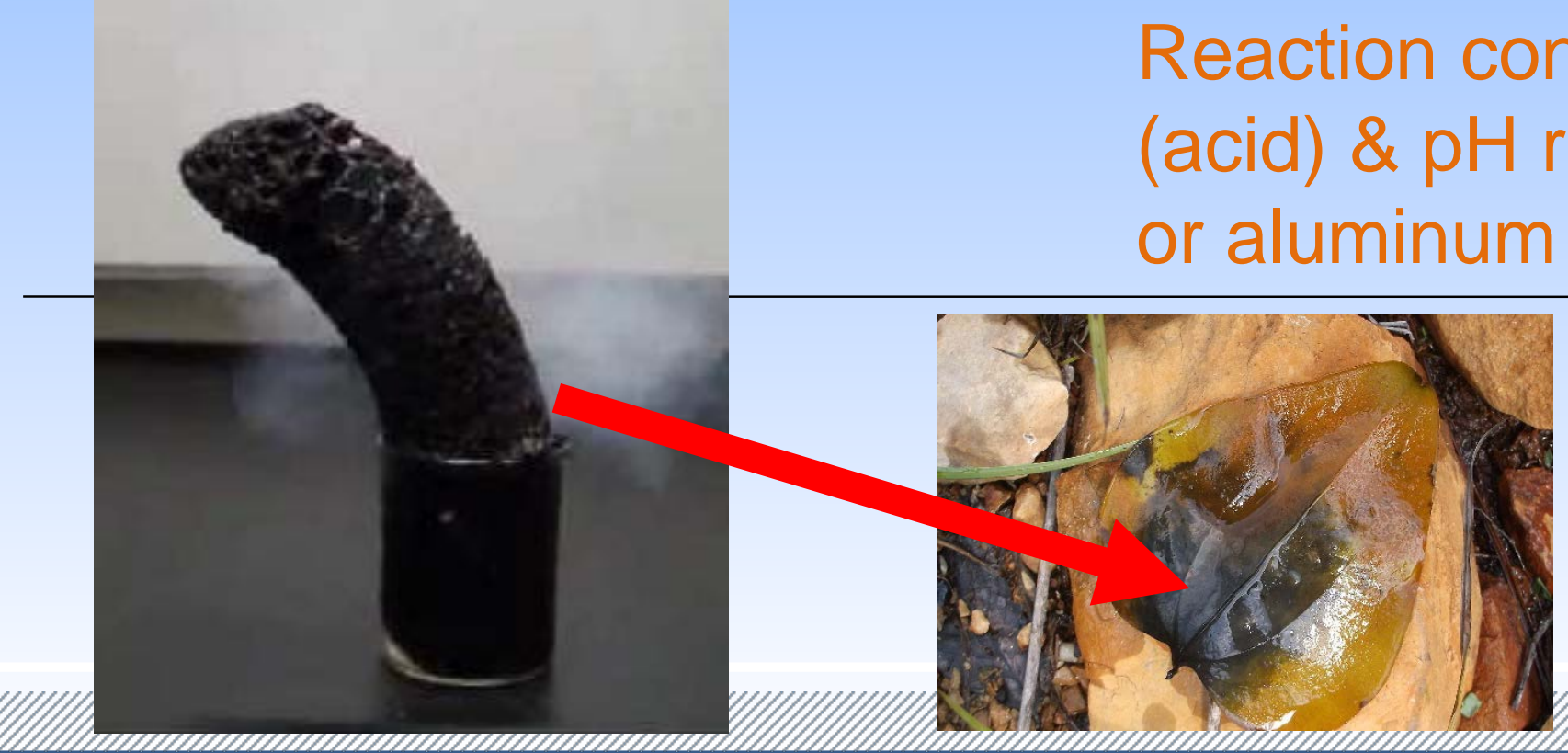




\section{Volunteer Aluminum Terrace Deposition Idaho}

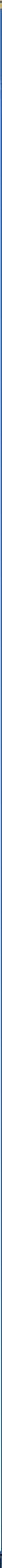




\section{Compare to Red and Bonita Mine Portal}

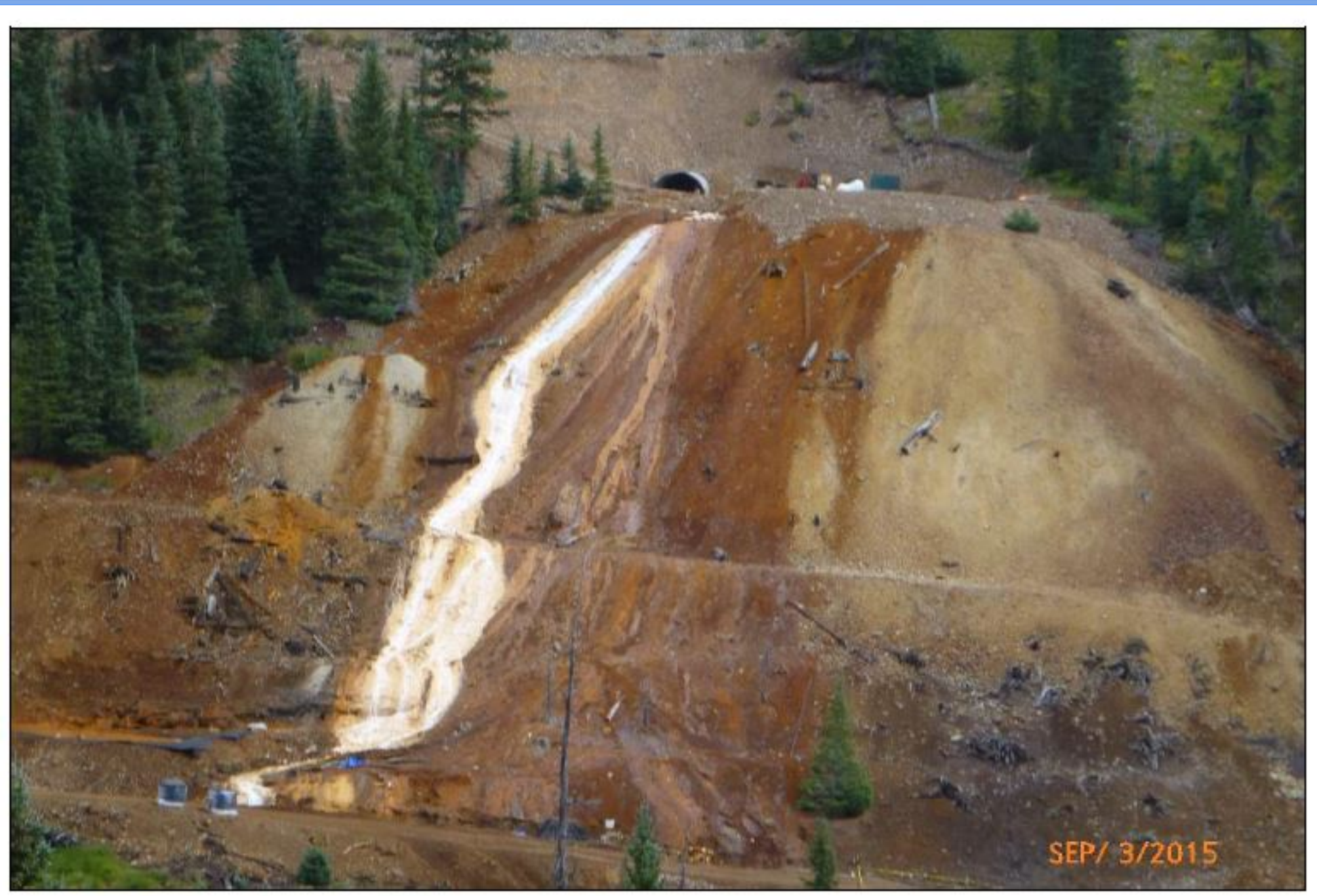

US Bureau of Reclamation, 2015 


\section{Manganese Oxidation at Neutral pH}

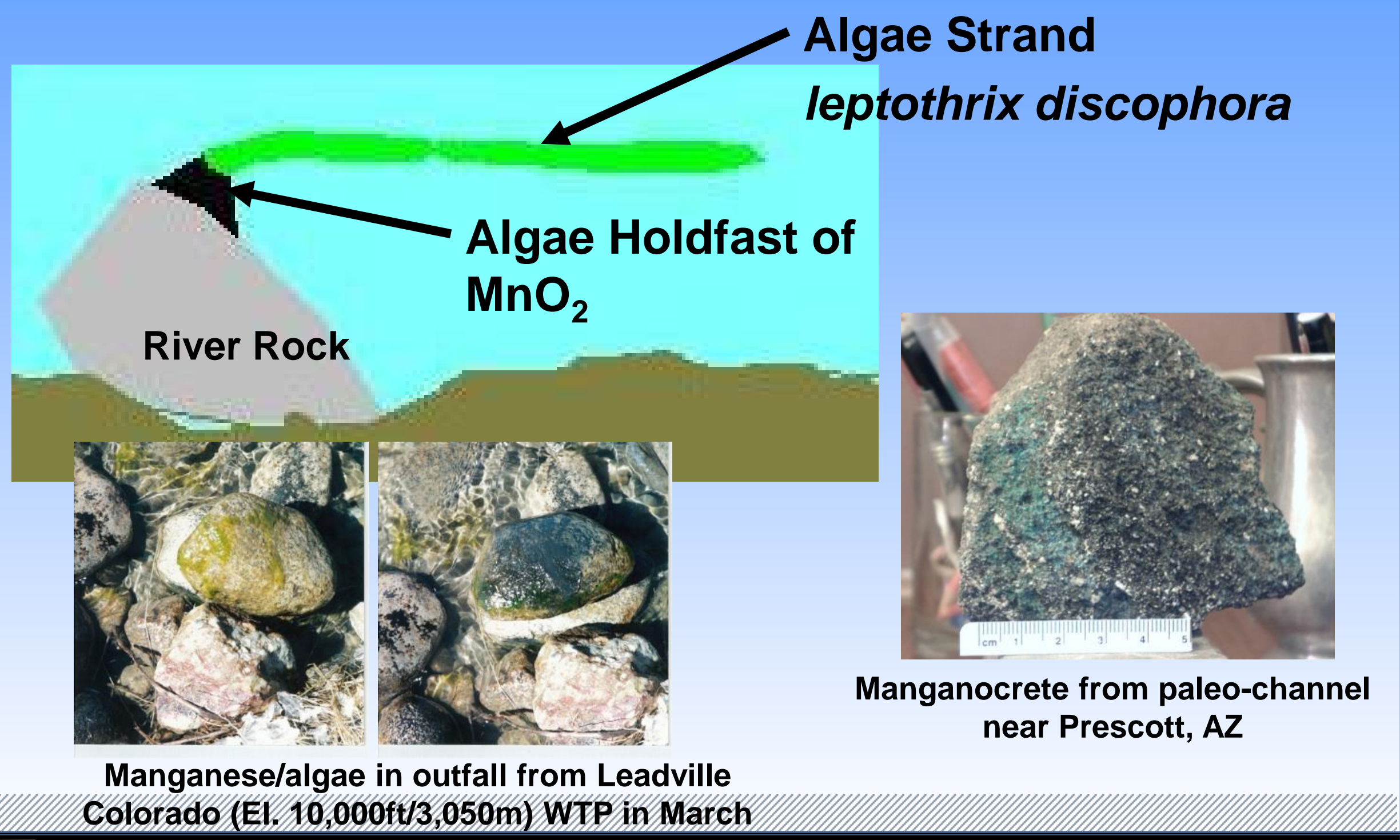




\section{Why is manganese removal so important?}

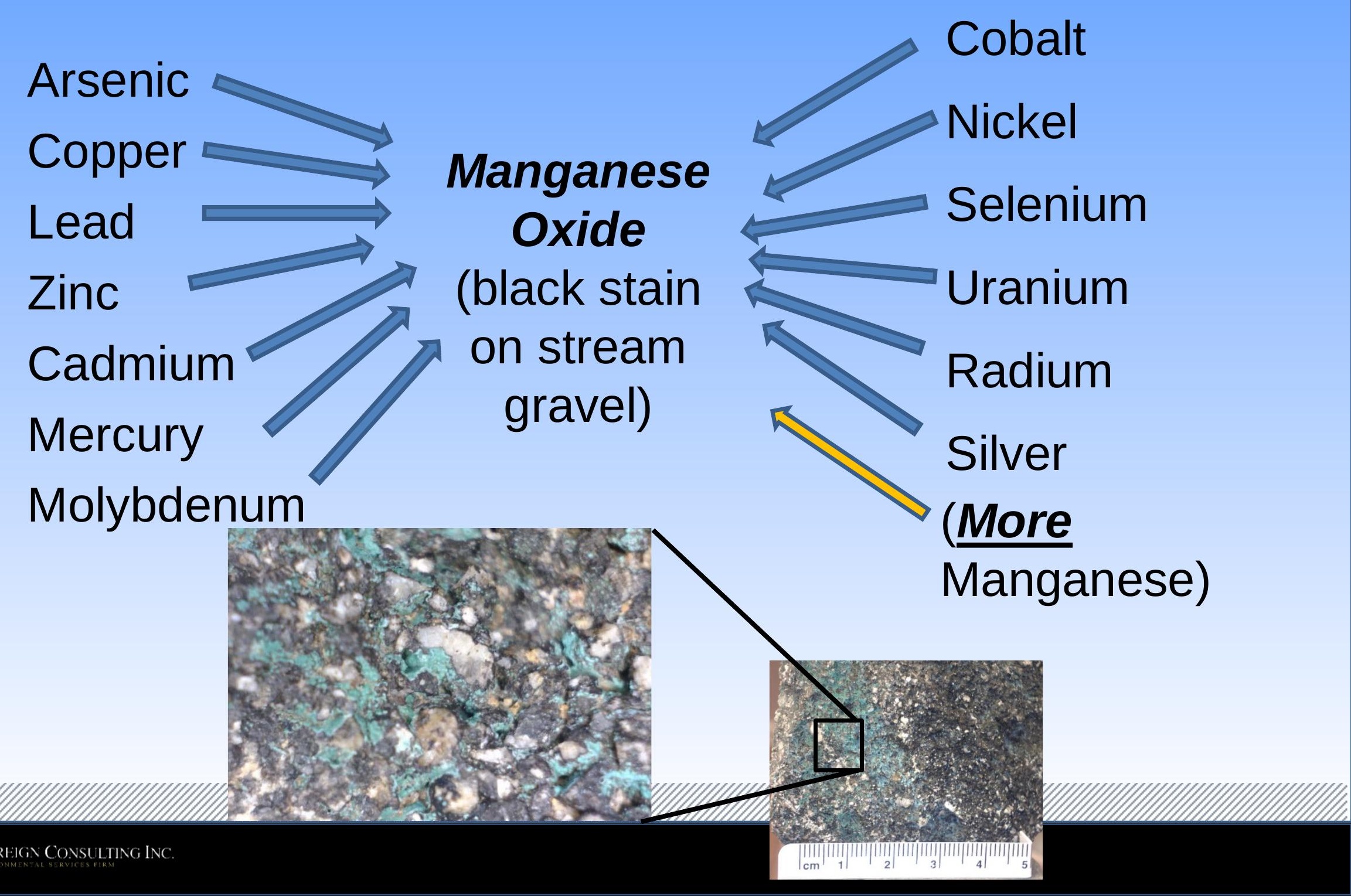




\section{The Gold King PTS Design Conditions}

\begin{tabular}{|l|c|l|l|}
\hline Parameter & Value & Units & Assumed Condition \\
\hline Flow & 300 & gpm & Spring freshet \\
\hline Flow & 200 & gpm & Steady state \\
\hline $\mathrm{pH}$ & 3.0 & $\mathrm{~S} . \mathrm{U}$. & Steady state \\
\hline Aluminum & 25 & $\mathrm{mg} / \mathrm{L}$ & Steady state \\
\hline Arsenic & 22 & $\mu \mathrm{g} / \mathrm{L}$ & Steady state \\
\hline Iron & 126 & $\mathbf{m g} / \mathbf{L}$ & Steady state \\
\hline Cadmium & 75 & $\mu \mathrm{g} / \mathrm{L}$ & Steady state \\
\hline Copper & 6.0 & $\mathbf{m g} / \mathbf{L}$ & Steady state \\
\hline Cobalt & 111 & $\mu \mathrm{g} / \mathrm{L}$ & Steady state \\
\hline Manganese & 35 & $\mathrm{mg} / \mathrm{L}$ & Steady state \\
\hline Sulfate & 1,760 & $\mathbf{m g} / \mathbf{L}$ & Steady state \\
\hline Zinc & 26 & $\mathbf{m g} / \mathbf{L}$ & Steady state \\
\hline
\end{tabular}




\section{Passive Treatment Decision Tree 2016}

\section{Gold King}

Conceptual PTS Design \#1

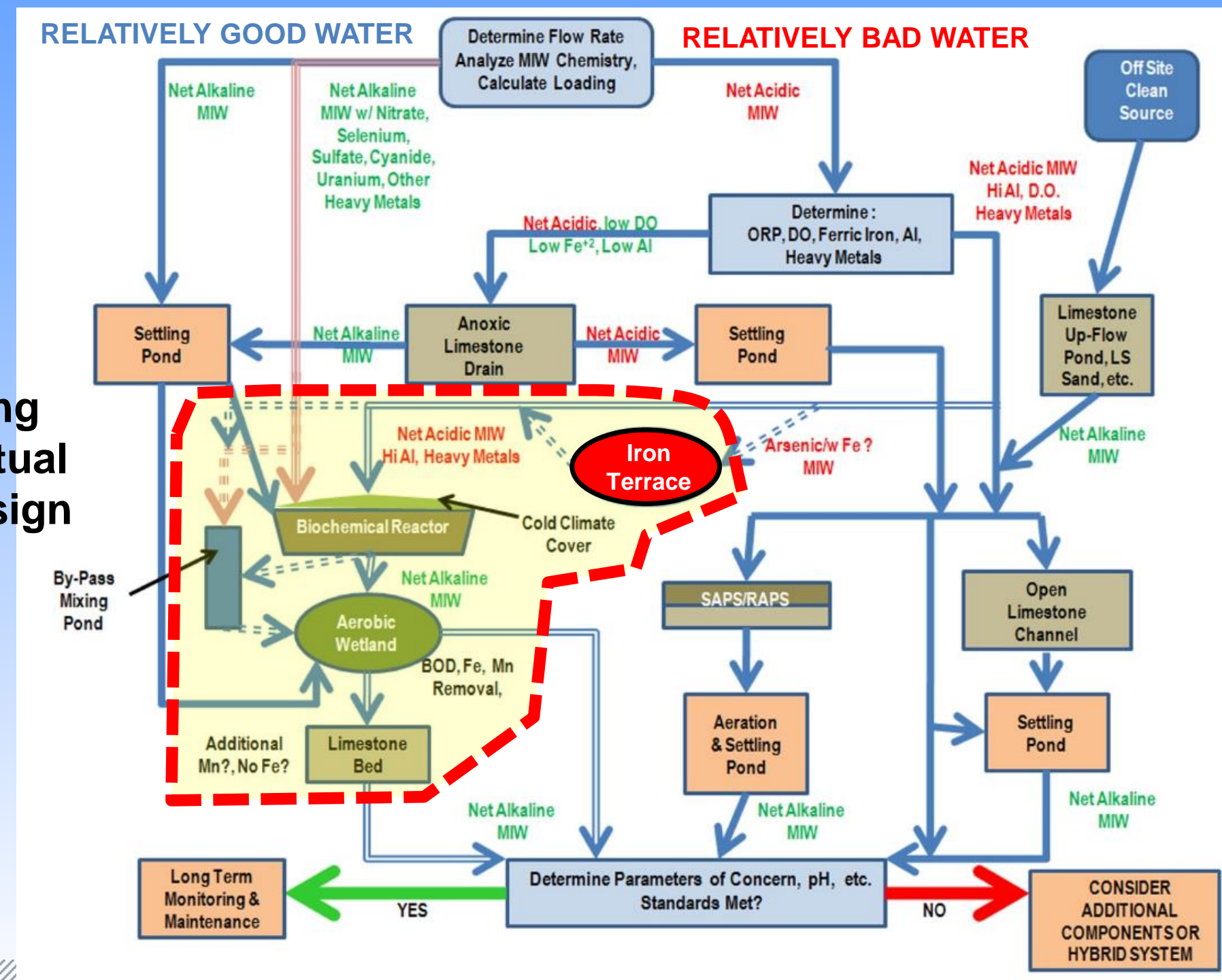




\section{Conceptual Gold King PTS \#1}

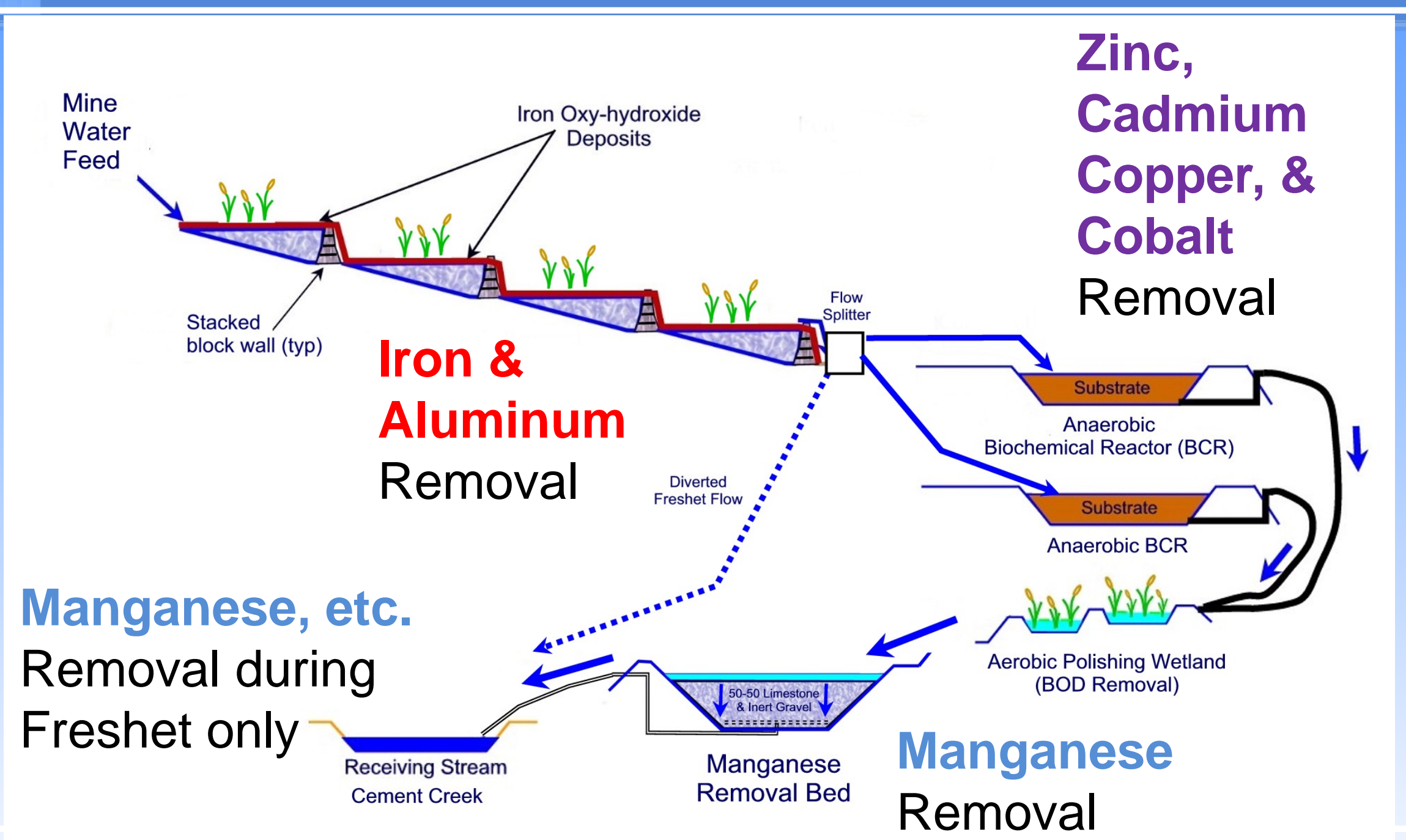




\section{Passive Treatment Decision Tree 2016}

\section{Gold King Conceptual PTS Design}

\#2

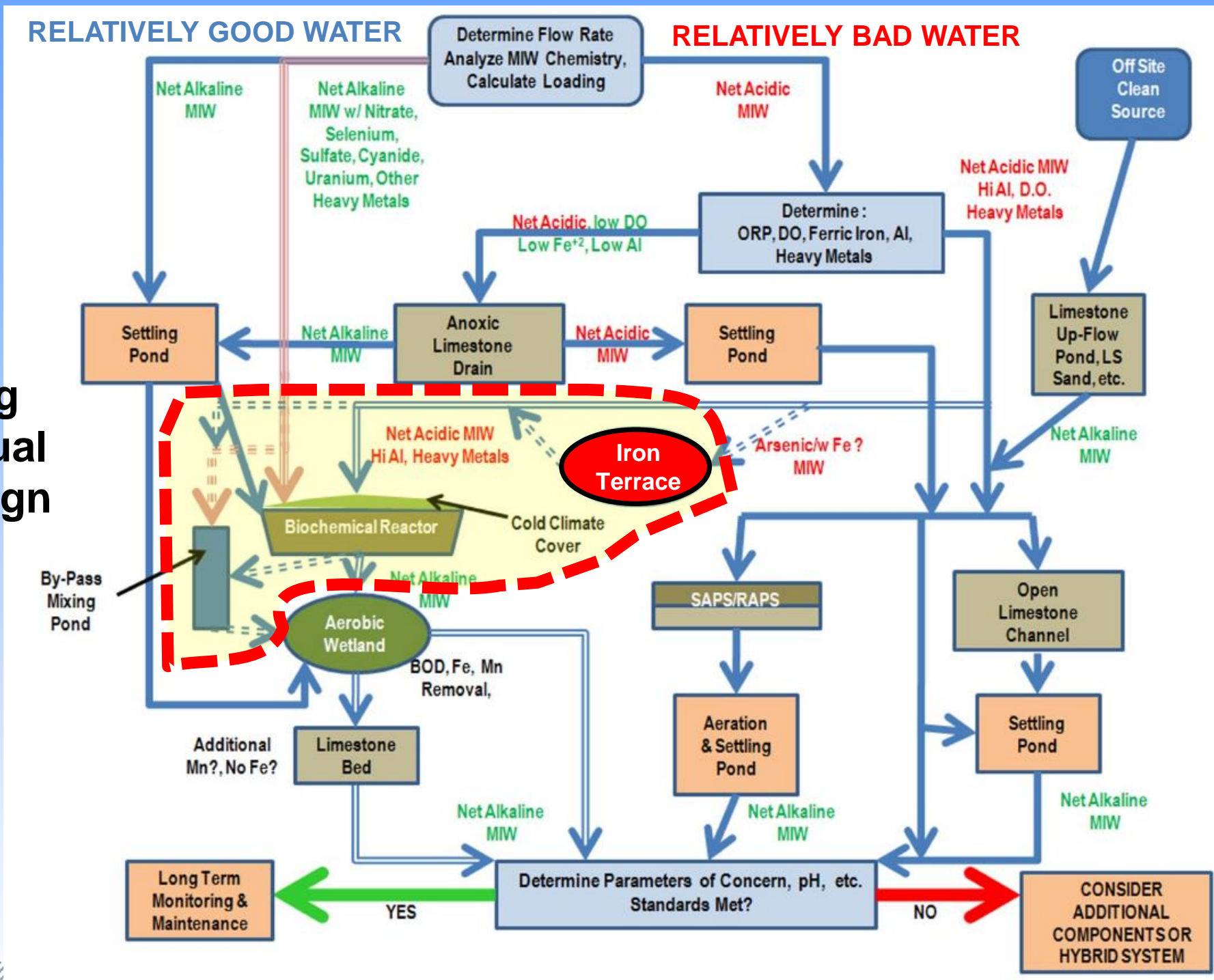




\section{Conceptual Gold King PTS \#2}

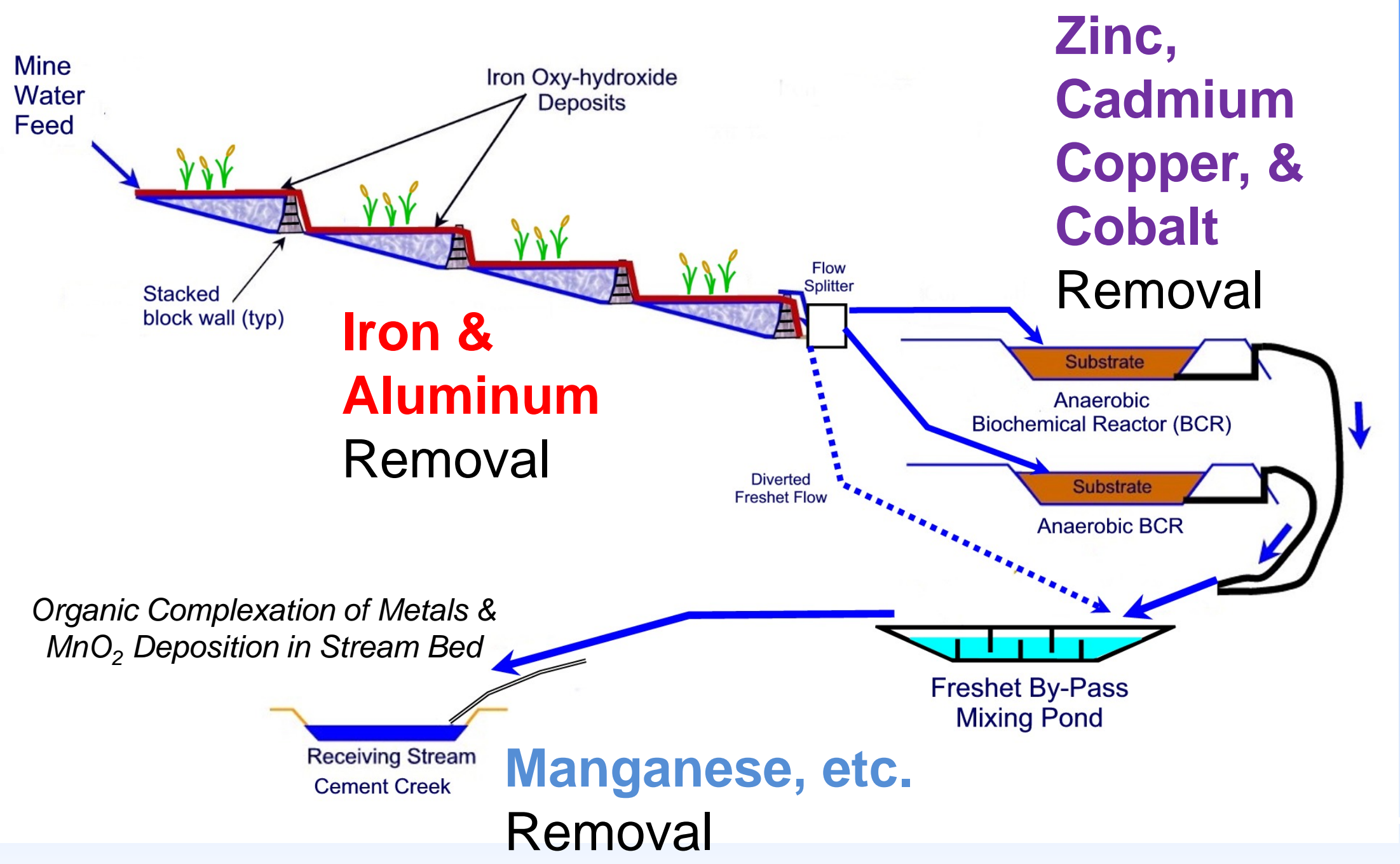




\section{Gold King PTS Sites?}

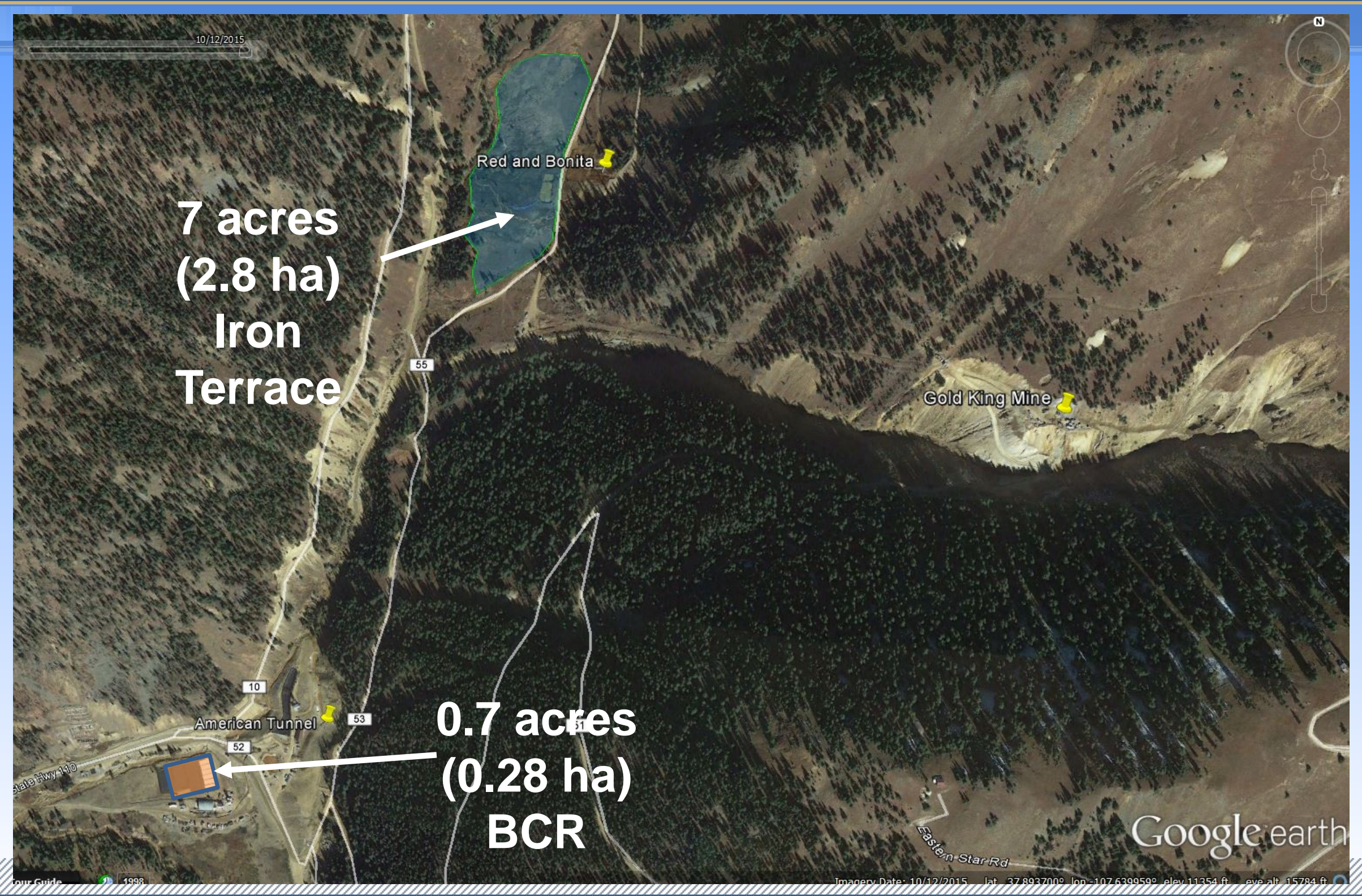




\section{Primary ARD Source Control}

\section{Tailings and Mine Waste Conference, Keystone Colorado Oct. 3-5, 2016}

\section{A Pathway to Walk-Away? - 30 Year Old Technology to Suppress Acid Rock Drainage Revisited}

- Use of bactericides to suppress ARD

- Seven case history successes

- Merging old and new technologies 


\section{REVIEW - Pathway to Walk-Away}

1. Primary Source Control to minimize flow, metals concentrations, and loading

2. Reclamation/Remediation to sustain primary source control measures for the long term

3. Passively Treat residual conditions

- $\mathrm{pH} 2.5$ to 8.5

- Metals (Fe, Cu, Pb, Zn, Cd, Cr, Mn, Hg, Mo, Al, $\mathrm{Se}, \mathrm{As}, \mathrm{U}, \mathrm{Co}, \mathrm{Tl})$

- Non-metals ( $\left.\mathrm{CN}, \mathrm{SO}_{4}, \mathrm{NO}_{3}, \mathrm{NH}_{3}, \mathrm{BOD}_{5}, \mathrm{P}\right)$

- Temperatures (0 to 30 deg $\mathrm{C}$ )

- Major processes are:

- Chemical precipitation (usually facilitated by bugs) in aerobic and anaerobic conditions

- Adsorption to $\mathrm{MnO}_{2}$, etc. (facilitated by algae) 


\section{Thank You}

"In the fields of observation, chance favors only the prepared mind."

L. Pasteur

\section{igusek@sovcon.com}

